\title{
Commentary: Readmissions after complex general thoracic @ check for updates surgery: Can we catch them before they fall?
}

\author{
Gita N. Mody, MD, MPH
}

\footnotetext{
From the Division of Cardiothoracic Surgery, Department of Surgery, University of North Carolina, Chapel Hill, NC

Disclosures: Author has nothing to disclose with regard to commercial support.

Received for publication April 23, 2019; accepted for publication April 24, 2019; available ahead of print June 12, 2019.

Address for reprints: Gita N. Mody, MD, MPH, Division of Cardiothoracic Surgery, University of North Carolina, Burnett-Womack Building Ste 3041, Campus Box 7065, Chapel Hill, NC 27599-7065 (E-mail: gita_mody@ med.unc.edu).

J Thorac Cardiovasc Surg 2019;158:943-4

$0022-5223 / \$ 36.00$

Copyright (C) 2019 by The American Association for Thoracic Surgery

https://doi.org/10.1016/j.jtcvs.2019.04.072
}

Hospital readmission rates are used to judge the quality of surgical care. Although reasons for postoperative readmissions are multifactorial, lower readmission rates have been seen in patients undergoing operations at centers with high surgical volume and low surgical mortality. ${ }^{1}$ Unplanned readmissions are costly and taxing for patients and providers, so the Centers for Medicare and Medicaid Services Hospital Readmissions Reduction Program financially penalizes facilities with higher than expected readmission rates for select medical diagnoses. In 2015, the Hospital Readmissions Reduction Program expanded to include excess postoperative readmissions after coronary artery bypass grafting and hip and knee replacements. ${ }^{2}$

It is possible that readmissions after other operations also will be penalized in the future. Therefore, examining contributors to readmissions and interventions to improve rates is necessary. However, the expected rate of readmissions after complex general thoracic oncologic surgery, how many of these readmissions are preventable, and whether reduction in readmission rates leads to overall care improvement for patients are unknown.

To answer these questions, Gupta and colleagues ${ }^{3}$ sought to understand the influence of regionalized care in Canada on readmission rates after esophagectomy for esophageal cancer. They performed a retrospective analysis of several linked administrative data sources and found $27.9 \%$ of esophagectomy patients were readmitted within 90 days of discharge. Readmission rates at high-volume regionalized thoracic centers were no different than at other hospitals and did not change with the introduction of regionalization.

In the analysis, the quality indicators of surgical volume and perioperative mortality had no association with readmission rates. This may be due to medical comorbidities of patients with esophageal cancer and use of multimodality treatments with significant side effects. Of note, postoperative complications were associated with readmissions after esophagectomy, as has been found in other studies of

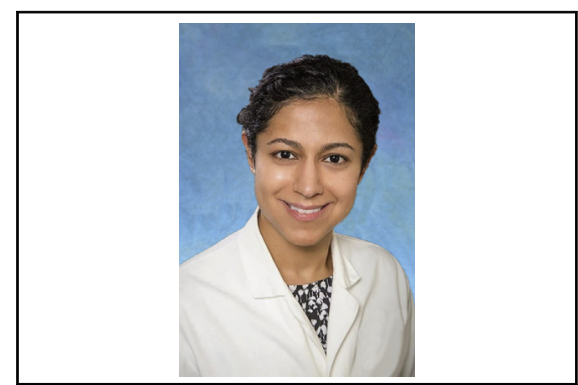

Gita N. Mody, MD, MPH

Central Message

Reasons for readmission after esophagectomy are multifactorial. Efforts to understand contributors will lead to interventions that improve not only readmission rates but also overall care of patients.

See Article page 934.

patients undergoing thoracic surgery. ${ }^{4,5}$ The authors conclude that despite the improvements that regionalized cancer care has offered in Canada, there is a minimum number of readmissions that can be expected after esophagectomy. The question remains: Is this the best we can do, or, can we catch postoperative patients at risk for readmission before they fall off the path to safely getting home?

Gupta and colleagues ${ }^{3}$ make a valuable contribution to surgical outcomes research. Their large study using population-based data for all hospitals in their region allows us to identify a population at risk for readmission. However, this secondary data analysis does not allow direct testing of the hypothesis that universal health care and regionalized care affect postoperative readmission rates. Their data suggest that addressing care processes around the highestburden symptoms after esophagectomy, specifically gastrointestinal issues, may help reduce readmission rates. Areas for future intervention include increasing access to care, anticipatory guidance, and/or remote active symptom management. Further, by engaging patients in improving the readmissions prevention process, we can gain valuable insights that will ultimately strengthen the care we provide. ${ }^{6}$

\section{References}

1. Tsai TC, Joynt KE, Orav EJ, Gawande AA, Jha AK. Variation in surgicalreadmission rates and quality of hospital care. N Engl J Med. 2013;369:1134-42. 
2. Hospital Readmissions Reduction Program. Available at: https://www.cms.gov/ Medicare/Medicare-Fee-for-Service-Payment/AcuteInpatientPPS/ReadmissionsReduction-Program.html. Accessed May 20, 2019.

3. Gupta V, Bubis L, Kidane B, Mahar AL, Ringash J, Sutradhar R, et al. Readmission rates following esophageal cancer resection are similar at regionalized and non-regionalized centers: a population-based cohort study. J Thorac Cardiovasc Surg. 2019;158:934-42.

4. Jean RA, Chiu AS, Boffa DJ, Detterveck FC, Blasberg JD, Kim AW. When good operations go bad: the additive effect of comorbidity and postoperative complications on readmission after pulmonary lobectomy. Surgery. 2018;164: 294-9.

5. Bhagat R, Bronsert MR, Juarez-Colunga E, Weyant MJ, Mitchell JD, Glebova NO, et al. Postoperative complications drive unplanned readmissions after esophagectomy for cancer. Ann Thorac Surg. 2018;105: 1476-82.

6. Howard-Anderson J, Lonowski S, Vangala S, Tseng CH, Busuttil A, AfsarManesh N. Readmissions in the era of patient engagement. JAMA Intern Med. 2014;174:1870-2. 